\title{
Avaliação da política educacional municipal: em busca de indicadores de efetividade nos âmbitos do acesso, gestão e financiamento
}

Andréa Barbosa Gouveia*

\section{Resumo}

0 artigo discute indicadores para avaliação da política educacional municipal produzida por partidos de perfis antagônicos no cenário brasileiro, priorizando dimensões quantificáveis nos âmbitos do acesso, gestão e financiamento da educação que possam expressar efetividade objetiva da política educacional no ciclo de uma gestão, (FIGUEIREDO, A. M. C.; FIGUEIREDO, M. F., 1986). A discussão é parte de pesquisa documental de fontes indiretas nacionais e de fontes diretas de duas administrações municipais. 0 levantamento refere-se ao ciclo da gestão 2001-2004; a pesquisa de campo foi realizada entre 2005 e 2007. Os indicadores propostos são aplicados em uma administração do PT em Londrina e PFL em Curitiba. Os resultados encontrados na pesquisa parecem confirmar o potencial destes indicadores para diferenciar os efeitos das opções de cada administração na cobertura do atendimento, na democratização das relações na rede de ensino, na escola e no incremento de investimento anual.

Palavras-chave: Política educacional. Municipios. Avaliação. Indicadores.

\section{Evaluation of municipal educational policy: seeking for indicators of effectiveness in the access, management and financing area Abstract}

This article discusses pointers to evaluate the municipal educational policy built up by parties with antagonistic profiles in the Brazilian scenario, prioritizing measurable dimensions in the areas of access, management and financing of education which are able to demonstrate objective effectiveness of the educational policy in a cycle of management, (FIGUEIREDO, A. M. C.; FIGUEIREDO, M. F., 1986). The discussion is part of a documentary research of indirect national

\footnotetext{
* Doutora em Educação, Universidade de São Paulo (USP); Professora da Universidade Federal do Paraná (UFPR). E-mail:andreabg@ufpr.br
} 
sources and direct sources of two municipal administrations. The survey refers to the 2001-2004 management cycle, the field research was carried out between 2005 and 2007. The proposed indicators are applied in a PT's administration in Londrina and PFL's in Curitiba. The results of the research seemed to confirm these pointers' potential to distinguish the effects of the options of each administration in terms of care, democratization of relationships in the educational system and in school and in the increase of the annual investment. Keywords: Educational policies. Municipalities. Assessment. Indicators.

\section{Evaluación de la política educacional municipal: en busca de indicadores de efetividad en los ámbitos del acceso, gestión y financiación. Resumen}

El artículo analiza los indicadores para evaluar la política educativa municipal producidos por los partidos políticos opuestos en el escenario brasileño, dando prioridad a las dimensiones mensurables en las áreas de acceso, gestión y financiación de la educación que pueden expresar la eficacia de la política educativa en un ciclo de la gestión, (FIGUEIREDO, A. M. C.; FIGUEIREDO, M. F., 1986). El debate es parte de la investigación documental y de fuentes nacionales indirectas y de fuentes directas de las administraciones municipales. La encuesta se refiere a la gestión del ciclo 2001-2004, la investigación de campo se llevó a cabo entre 2005 y 2007. Los indicadores propuestos se aplican en una administración de PT en Londrina y de PFL en Curitiba. Los resultados parecen confirmar el potencial de investigación de estos indicadores para diferenciar los efectos de las opciones para cada administración en la cobertura de atención en la democratización de las relaciones en el sistema de educación y en la escuela y el aumento de la inversión anual.

Palabras clave: Política educativa. Los municipios. Los indicadores de evaluación.

\section{Introdução}

0 grau de descentralização do sistema educacional brasileiro exige que a avaliação de efetividade da política educacional incorpore a sua dinâmica municipal. Este espaço de atendimento educacional é marcado pelas decisões políticas nacionais, tanto quanto pela diversidade de diálogos com aquelas políticas. Se este é um diálogo direto com o que pode ser considerado hegemônico no cenário educacional nacional, também é um diálogo indireto com as disputas entre perspectivas divergentes de política educacional.

Uma revisão da literatura deste campo permite sintetizar as tensões entre projetos para a política educacional em termos de mercado e cidadania, expressos em binômios como produtividade / democratização (SANDER, 2005); gerencialismo/ de-

Ensaio: aval. pol. públ. Educ., Rio de Janeiro, v. 17, n. 64, p. 449-476, jul./set. 2009 
mocratização (PERONI, 2003; ADRIÃO, 2006); conservação / transformação (PARO, 1996); regulação/ emancipação (AFONSO, 2002). Neste artigo esta tensão no campo educacional é caracterizada em termos político-partidários num diálogo com a literatura do campo da ciência política que reconhece que, ainda que com limites, há no Brasil partidos que podem ser caracterizados como antagônicos no binômio esquerda/ direita (LIMONGI; FIGUEIREDO, 1995; SANTOS; VILAROUCA, 2004; RODRIGUES, 2002; SCALON, 2004). Em que pese polêmicas quanto aos partidos de centro, os estudos são enfáticos em contrapor o Partido dos Trabalhadores (PT) e o Partido da Frente Liberal (PFL)' como pólos antagônicos no espectro político brasileiro.

Este artigo analisa duas administrações municipais paranaenses, Curitiba na gestão de Cássio Taniguchi do PFL e Londrina na gestão de Nedson Micheleti do PT. Ainda que a realização das políticas pudesse incorporar uma discussão acerca das intencionalidades de cada administração, o recorte aqui procura privilegiar a avaliação da administração municipal a partir de indicadores quantitativos que possam expressar a efetividade da política educacional no ciclo de uma gestão, efetividade entendida em sua dimensão objetiva como "critério de aferição da mudança quantitativa entre o antes e o depois da execução" da política (FIGUEIREDO, A. M. C.; FIGUEIREDO, M. F., 1986, p. 116).

Na construção de indicadores de efetividade da gestão municipal, ainda que se possa considerar o tempo de uma administração um intervalo muito curto para avaliação de impacto de políticas educacionais, intenciona-se ajudar a enfrentar um problema de fundo na ação governamental: a descontinuidade das ações. Historicamente constatase que entre as gestões na área educacional não há necessariamente continuidade, o que pode tornar-se uma armadilha, visto que não se têm impactos da politica para serem avaliados e se altera a politica sem considerar seus impactos. Portanto, ainda que a dificuldade temporal seja pertinente, buscar-se-ão elementos que, ao menos, constituam-se indícios de resultados das políticas em cada ciclo de administração pública.

A discussão aqui proposta é uma parte de pesquisa documental de fontes indiretas, disponíveis nos órgãos nacionais e de fontes diretas, coletadas em cada administração municipal. 0 levantamento refere-se ao ciclo da gestão municipal 20012004, sendo que a pesquisa de campo foi realizada entre 2005 e 2007.

\section{Partidos políticos no Brasil}

Em um primeiro momento importa apresentar, mesmo que de forma breve, o debate em que se contextualiza a opção pelo PT como expressão da esquerda e do PFL como expressão da direita no espectro partidário brasileiro. Esta opção sustenta-se em estudos sobre a movimentação dos maiores partidos no Congresso Nacional (LIMONGI; FIGUEIREDO, 1995; RODRIGUES 2002) e no estudo de Santos e Vilarouca

\footnotetext{
${ }^{1}$ Atual Democratas, como a mudança de nome do partido foi posterior a gestão estudada, optou-se por manter a denominação do período.
}

Ensaio: aval. pol. públ. Educ., Rio de Janeiro, v. 17, n. 64, p. 449-476, jul./set. 2009 
(2004), que atualizam o debate sobre partidos e a questão da igualdade, a partir de dados de um survey acerca da "Percepção da desigualdade" realizado pelo IUPERJ².

Santos e Vilarouca discutem a questão da percepção dos brasileiros sobre o compromisso dos partidos políticos em relação à superação das desigualdades e o fazem tendo como pressuposto uma distribuição partidária entre direita e esquerda. Santos e Vilarouca (2004) informam que, apesar dos dados do survey terem indicado que menos de 50\% da população brasileira tenha identificação partidária, entre os que se identificam com os partidos, ou identificam as posições dos diferentes partidos, o fazem de uma forma que torna possível reconhecer na organização partidária um espaço de informação política dos eleitores. Os dados de tal survey revelam uma indiferenciação entre os polos intermediários, mas reiteram a existência de diferenças entre as pontas e a localização nestas pontas de dois partidos, o PT e o PFL.

Estes são partidos importantes no cenário brasileiro por ocuparem um número grande de administrações municipais, pelo tamanho das bancadas no parlamento e por serem reconhecidos como de fato existentes na vida institucional brasileira, ou seja, não são partidos de "aluguel" em que os candidatos usam as legendas para o processo eleitoral, mas depois não mantêm organicidade ao longo dos mandatos.

Estudo de Melo (2000) acerca da composição das bancadas federais e a questão da migração entre os partidos demonstra que as taxas de migração do PT e do PFL estavam entre as menores na Câmara Federal; considerando o período de maio de 1985 a janeiro de $1999^{3}$; o balanço do autor é que no PFL havia 78,6\% de deputados não migrantes, enquanto, no PT, 94,4\% eram não migrantes (MELO, 2000). 0 autor chama ainda a atenção para o fato de que apesar de à direita do espectro político haver maior migração entre partidos, neste campo é o PFL que tem a menor migração ${ }^{4}$.

Assim, explicita-se aqui a pertinência da opção por tomar PT e PFL como polos contrários, para avançar na tese de que a política pública local é resultado de tensões entre projetos à esquerda e à direita do espectro político. A análise da ação desses partidos na condução de gestões municipais no âmbito educacional buscará a exemplaridade dos casos para análise da realidade brasileira, sem dúvida, sem a pretensão de esgotar as possibilidades destas experiências e nem a própria ação de cada um dos partidos em suas diferentes administrações. Considera-se ainda relevante, uma rápida digressão sobre a organização destes dois partidos e a relação destes com a formulação da política municipal.

\footnotetext{
${ }^{2} 0$ livro de Celi Scalon (2004) apresenta as principais conclusões do surveyem uma série de artigos que tomam pontos de vista diferentes para analisar a questão da desigualdade brasileira, aqui se apresenta a relação entre a percepção da desigualdade e os partidos políticos conforme artigo de Fabiano Santos e Marcio Grijó Vilarouca (2004).

${ }^{3}$ Apesar do estudo de Melo (2000) não contemplar o último período 200-2007, entende-se que não cabe neste trabalho atualizar os dados, posto que este não é um trabalho exclusivamente sobre partidos e se poderia cair em erros metodológicos para o cálculo.

${ }^{4}$ Outra informação interessante de Melo (2000) é que à esquerda há menor migração, porém a direita migra de forma mais coerente, ou seja, os deputados à direita migram entre os partidos que vão até o centro sem romper fronteiras ideologias; à esquerda quando há migração esta cruza fronteiras ideológicas.
} 
0 PFL foi criado em 1985, por uma dissidência do Partido Democrático Social (PDS), partido este que, apesar do nome, era um partido conservador de sustentação do regime militar (MAINWARING; MENEGUELLO; POWER, 2000). Desde sua criação, o PFL esteve entre os maiores partidos no Congresso Nacional ${ }^{5}$ e ocupou ministérios em todos os governos até 2003. Para a formação de quadros e o acompanhamento das administrações municipais, o PFL criou o Instituto Tancredo Neves (ITN), órgão que atua, também, como divulgador das experiências municipais exitosas do partido e como espaço de formulação e atualização do pensamento liberal do partido. Na página do ITN (2007) está disponivel uma série de vídeos "PFL em debate", parte da Escola Nacional de Governo do partido, pela qual é possivel acompanhar os debates acerca dos programas do governo federal, de temas de gestão urbana e de experiências municipais entre as quais está a da cidade de Curitiba na gestão Cássio Taniguchi, objeto de análise empírica deste artigo.

0 Partido dos Trabalhadores foi fundado em 1980, unindo militantes do novo sindicalismo, especialmente na Região Metropolitana de São Paulo, com militantes católicos, especialmente ligados à teologia da libertação, intelectuais e setores da classe média; o partido definiu-se desde sua criação como socialista e nasceu de forma atípica na democracia brasileira (KECK, 1991). 0 PT participou do primeiro processo eleitoral em 1982 e teve crescimento lento, mas contínuo desde então. Nas eleições legislativas federais conseguiu 3,5\% dos votos em 1982; 6,9\% em 1986; 10,2\% em 1990; 12,8\% em 1994; 13,2\% em 1998 e 18,4\% em 2002, quando elegeu o Presidente da República ${ }^{6}$ (SAMUELS, 2004). Uma das características que a literatura especializada destaca na vida partidária brasileira é a baixa identificação da sociedade com os partidos, isto faz com que o PT tenha um aspecto peculiar que é do alto grau de reconhecimento pelos eleitores. Uma das possibilidades de explicação para esta peculiaridade pode estar no fato de que o PT, desde o nascedouro, insistiu em atuar como partido.

Pode ainda ter contribuido para este processo de identificação entre os eleitores, o movimento que o PT fez em suas administrações de cunhar a expressão "modo petista de governar"7, forma de expressar o processo de aproveitamento das experiências bem-sucedidas do partido, especialmente em governos municipais, que foram alimentando cada nova administração. Nesse sentido, as experiências das prefeituras não são uma questão menor, visto que ai o partido teve um crescimento expressivo em termos de cidades que administrou de 1982 até $2002^{8}$, mas também é expressivo o número de estudos sobre tais experiências, certamente capitaneado

\footnotetext{
${ }^{5}$ O PFL tinha 23,8\% das cadeiras na Câmara Federal em 1986; 16,7\% em 1990; 17,3\% em 1994 e 20,5\% em 1998. Dados de TAROUCO (2002) informam que em 1988 o PFL administrava 24,6\% das prefeituras do pais, em 2000 administrava 18,5\%.

${ }^{6}$ Novamente optou-se por não atualizar os dados por fonte direta para evitar interpretações equivocadas das fontes.

${ }^{7}$ A Fundação Perseu Abramo (FPA), órgão de formação e divulgação politica do PT, por exemplo, informa em sua página que "o seminário 0 Modo Petista de Governar: $3^{a}$ Geração", organizado pela FPA, Secretaria Nacional de Assuntos Institucionais do PT e GTE, em Brasilia, nos dias 13, 14 e 15 de dezembro de 1996 contou com mais de quinhentos participantes" (FPA, 2007).

${ }^{8} \mathrm{Em} 1982$ o PT elegeu prefeito de duas cidades, Diadema, em São Paulo e Santa Quitéria no Maranhão; em 1985 elegeu o prefeito de Fortaleza; em 1988 elegeu prefeitos em 37 cidades entre elas São Paulo, Porto Alegre e Vitória; em 92 foram eleitos 54 prefeitos, em 1996 foram 115 prefeituras. Em 2000 foram eleitos 187 municipios ou 3,3\% das cidades brasileiras contra 1.028 cidades que tiveram prefeitos do PFL eleitos no mesmo pleito, ou 18,5\% das cidades brasileiras (FLEISCHER, 2002).
}

Ensaio: aval. pol. públ. Educ., Rio de Janeiro, v. 17, n. 64, p. 449-476, jul./set. 2009 
pelo sucesso da proposição do orçamento participativo, mas também pela exemplaridade de algumas experiências como a administração Erundina em São Paulo, Olivio Dutra e Tarso Genro em Porto Alegre, Patrus Ananias em Belo Horizonte.

\section{Direita e Esquerda na política educacional: um quadro de referência}

A análise da ação destes partidos no âmbito de duas Secretarias Municipais de Educação proposta aqui pressupõe a compreensão de que há uma diferenciação entre propostas para a ação do Estado e para a formulação e execução de políticas públicas entre os campos de direita e de esquerda. 0 suposto aqui, entretanto, não é que se encontrará no campo empírico a reprodução coerente de tal diferenciação, ao contrário, o suposto é que na ação concreta tais propostas são "borradas" e cada partido acaba respondendo a demandas do campo antagônico. Isto não descarta a existência de disputas entre projetos, porém explicita que na dinâmica social direita e esquerda acabam fazendo concessões, que são compreendidas aqui, como resultado do próprio processo de conflito.

Para situar de forma breve esta disputa parece interessante recorrermos ao debate sobre o papel do Estado na produção e implementação de políticas públicas; para isto o argumento de Raichelis (2006, p. 22, grifo do autor) é uma boa sintese do conflito:

Trata-se de uma dinâmica que reforça a dualização existente no campo das políticas sociais e da gestão pública: ao Estado cabe garantir o mínimo ao conjunto da população excluída do mercado de trabalho ou em situação de inclusão extremamente precária e desprotegida, por meio de políticas compensatórias, focalizadas e seletivas, para atenuar o impacto negativo das medidas econômicas de ajuste estrutural - é a "pobre política para os pobres". E ao mercado cabe a venda de serviços aos trabalhadores formais, cada vez em menor número, promovendo a remercantilização dos serviços sociais consagrados como direitos no decorrer das lutas históricas do movimento dos trabalhadores. Esse mesmo movimento desencadeia a privatização dos serviços urbanos, reconfigurando a produção das cidades e dos seus territórios, transformando simultaneamente as relações entre cidadãos e espaços das lutas por acesso à cidade e a melhorias na qualidade da vida urbana.

É inegável que a lógica de descentralização de políticas sociais, que colocou o município no cerne do atendimento da população em diferentes áreas e, no caso da educação, colocou o atendimento da educação infantil e fundamental como priori-

Ensaio: aval. pol. públ. Educ., Rio de Janeiro, v. 17, n. 64, p. 449-476, jul./set. 2009 
dades das cidades, implicam opções do poder local sobre como atender as demandas dai decorrentes. Especialmente, interessa refletir sobre as tensões geradas para o financiamento e a gestão destas políticas: em termos do financiamento das políticas públicas o que está em jogo é a disputa pela ampliação de recursos versus redução de recursos, em nome do aumento da eficácia no uso dos recursos existentes. Em termos de gestão, a eficácia do uso de recursos implicará uma disputa entre uma perspectiva de inclusão e transparência da gestão e uma perspectiva que, embora nunca negue a necessidade de maior inclusão e de maior transparência, em geral subordina-a a ideia de sustentabilidade que incorpora a preservação, em última instância, da produtividade do sistema.

Os desdobramentos disso assumem feições especializadas em cada campo específico das questões sociais. No caso da educação, propõe-se um quadro de referência (Quadro 1), como síntese de projetos de política educacional expressos em estudos de diferentes experiências municipais de gestão educacional pós- 1988 e, ainda, expressos em proposições presentes na literatura de política educacional.

\begin{tabular}{|c|c|c|c|}
\hline 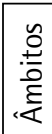 & Desdobramentos & $\begin{array}{l}\text { Esquerda } \\
\text { - Perspectiva democrática }\end{array}$ & $\begin{array}{l}\text { Direita } \\
\text { - Perspectiva gerencial }\end{array}$ \\
\hline \multirow[b]{2}{*}{ 娄 } & & $\begin{array}{l}\text { Educação articulada à } \\
\text { transformação }\end{array}$ & $\begin{array}{l}\text { Educação articulada à } \\
\text { formação para a sociedade } \\
\text { existente }\end{array}$ \\
\hline & & $\begin{array}{l}\text { Política educacional } \\
\text { articulada a ideia de direito } \\
\text { social e de atendimento das } \\
\text { necessidades de todos. }\end{array}$ & $\begin{array}{l}\text { Politica educacional } \\
\text { articulada à ideia de direito } \\
\text { social e de oferta de } \\
\text { oportunidades segundo as } \\
\text { habilidades de cada um. }\end{array}$ \\
\hline \multirow{5}{*}{ 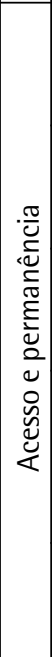 } & Condições básicas & $\begin{array}{l}\text { Igualdade de condições de } \\
\text { oferta para o conjunto da } \\
\text { população. }\end{array}$ & $\begin{array}{l}\text { Respeito às necessidades e } \\
\text { escolhas seja dos estudantes } \\
\text { ou das famílias. }\end{array}$ \\
\hline & Educação Infantil & $\begin{array}{l}\text { Universalização a partir do } \\
\text { direito das crianças. }\end{array}$ & $\begin{array}{l}\text { Atendimento da demanda } \\
\text { com ênfase em parcerias e na } \\
\text { assistência às famílias carentes. }\end{array}$ \\
\hline & \begin{tabular}{|l|} 
Ensino fundamental \\
\end{tabular} & $\begin{array}{l}\text { Universalização do } \\
\text { atendimento como direito } \\
\text { de todos. }\end{array}$ & $\begin{array}{l}\text { Universalização de } \\
\text { oportunidades segundo a } \\
\text { necessidade de cada um. }\end{array}$ \\
\hline & EJA & $\begin{array}{l}\text { Compromisso social: } \\
\text { envolvimento de segmentos } \\
\text { organizados da comunidade }\end{array}$ & $\begin{array}{l}\text { Segundo a demanda:à distância } \\
\text { Envolvimento da comunidade } \\
\text { na captação de recursos e na } \\
\text { execução de projetos. }\end{array}$ \\
\hline & Educação Especial (Inclusão) & $\begin{array}{l}\text { Inclusão com um modelo } \\
\text { universal sob responsabilidade } \\
\text { do poder público }\end{array}$ & Atendimento filantrópico \\
\hline
\end{tabular}

Ensaio: aval. pol. públ. Educ., Rio de Janeiro, v. 17, n. 64, p. 449-476, jul./set. 2009 
Continuação

\begin{tabular}{|c|c|c|c|}
\hline \multirow{3}{*}{ 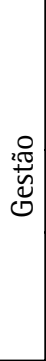 } & Mecanismos de gestão & $\begin{array}{l}\text { Democrática e participativa, } \\
\text { ênfase na organização de } \\
\text { conselhos no sistema e na } \\
\text { escola. }\end{array}$ & $\begin{array}{l}\text { Gerencial com ou sem } \\
\text { participação }\end{array}$ \\
\hline & $\begin{array}{l}\text { Papel da comunidade } \\
\text { escolar }\end{array}$ & Participar nas deliberações. & Participar na administração. \\
\hline & Avaliação & $\begin{array}{l}\text { Formativa, processual, nas } \\
\text { instituições como parte do } \\
\text { processo pedagógico. }\end{array}$ & $\begin{array}{l}\text { Mecanismo de regulação do } \\
\text { sistema educacional. }\end{array}$ \\
\hline \multirow{3}{*}{ 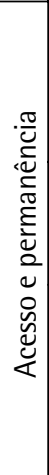 } & $\begin{array}{l}\text { Posição quanto ao } \\
\text { investimento }\end{array}$ & $\begin{array}{l}\text { Ênfase no investimento } \\
\text { social e na ampliação de } \\
\text { recursos. }\end{array}$ & $\begin{array}{l}\text { Ênfase na economia de } \\
\text { recursos e na ideia de que é } \\
\text { suficiente melhorar a gestão } \\
\text { dos recursos. }\end{array}$ \\
\hline & Politicas de recursos & $\begin{array}{l}\text { Aumento de investimento } \\
\text { em profissionais da } \\
\text { educação }\end{array}$ & $\begin{array}{l}\text { Aumento de investimento em } \\
\text { serviços de terceiros }\end{array}$ \\
\hline & Recursos na escola & $\begin{array}{l}\text { Repasse de recursos } \\
\text { articulado ao projeto } \\
\text { pedagógico e a critérios de } \\
\text { promoção da igualdade de } \\
\text { condições de oferta }\end{array}$ & $\begin{array}{l}\text { Repasse de recursos } \\
\text { articulado a economia de } \\
\text { recursos e a critérios de } \\
\text { eficiência. }\end{array}$ \\
\hline
\end{tabular}

Quadro 1- Características da política educacional em dois eixos: a direita e a esquerda. Fonte: A autora (2008).

Obs.: ${ }^{* *}$ pressupostos para política educacional.

Inicialmente observe-se que a própria concepção de educação, seguida pela concepção de justiça estarão na base das escolhas para as diferentes formas de garantir a política pública de educação, assim como as políticas públicas em geral. Políticas de esquerda podem ser proclamadas justas tanto quanto as de direita, se compreender-se que ideia de justiça sustenta cada extremo ${ }^{9}$.

Na implementação das políticas propõe-se que a análise tome indicadores de efetividade quanto ao atendimento (acesso), ao financiamento e à gestão da política educacional. 0 primeiro âmbito considerado na política educacional situa o desafio de prover o acesso e a permanência das crianças na escola, o desdobramento disto implica condições básicas para este acesso, por exemplo, à escola obrigatória (ensino fundamental), educação infantil, no atendimento à educação de jovens e adultos e à educação de pessoas com necessidades educativas especiais ${ }^{10}$.

\footnotetext{
${ }^{9}$ Para conceito de justiça social, ver Figueiredo (1997).

${ }^{10}$ Este artigo está articulado a pesquisa acerca da política educacional nos municípios brasileiros, por isso o acesso será discutido a partir das etapas da educação básica de responsabilidade municipal.
} 
Como condição básica entende-se aqui, num modelo à esquerda, a oferta de vagas públicas que pressuponha universalidade e igualdade desta oferta; assim temos a ampliação de vagas em escolas públicas diretas mantidas plenamente pelo Estado. No polo à direita, as últimas décadas apresentam uma série de alternativas em que a oferta pública se combina com as formas de escolha das familias.

No âmbito da gestão é conveniente, primeiro, observar como os diferentes procedimentos são propostos e, em seguida, no leque de possibilidades disponíveis, que instâncias de gestão são priorizadas e como elas são articuladas. Segundo, quando a comunidade escolar (pais, professores, alunos, funcionários) é chamada a participar cabe considerar onde está a ênfase da participação: no controle social sobre a escola e na definição dos rumos da politica educacional? - o que chamaremos aqui de deliberação. Ou a ênfase está na participação em ações pontuais que têm relação com a administração ou execução de tarefas? - o que chamaremos aqui de participação na administração, ou participação subordinada" ${ }^{11}$

Quanto ao financiamento, em termos gerais, podemos indicar que à direita encontra-se uma ênfase na economia de recursos e na tese de que o que é preciso melhorar é apenas a gestão dos recursos, dado que estes já são suficientes. A forma da gestão do recurso coincide com uma estratégia de diminuição Estado, por isso, entre as caracteristicas de uso dos recursos estará um aumento no investimento em serviços de terceiros e a descentralização de recursos com repasse para as unidades escolares públicas ou privadas, articulado à economia de recursos e a critérios de eficiência.

À esquerda pode-se identificar uma perspectiva de ampliação do investimento em educação, esta compreendida como investimento social; ênfase na transparência e no controle social do uso dos recursos, um aumento de investimento em profissionais da educação e repasse de recursos, isto articulado ao projeto pedagógico e a critérios de promoção da igualdade de condições de oferta entre as unidades escolares. De certa forma a separação entre gestão e financiamento é mais didática que real, visto que, se não se entende o financiamento de forma restrita, ele é parte imprescindivel da própria gestão do sistema educacional.

Caracterizar os embates no campo educacional em termos de direita e esquerda pode não refletir o que os partidos políticos hoje distribuídos no espectro político brasileiro propõem para a educação. Entretanto, a proposta é articular dois campos de debates para construir um quadro de referência que permita um caminho para a avaliação da efetividade objetiva da política: primeiro, considerou-se o que temos de consenso na literatura sobre partidos políticos, quanto a quais dos maiores partidos presentes no cenário nacional podem ser identificados como atores de direita e de esquerda; frente a este quadro escolheram-se duas experiências para estudar; segundo, considerou-se no debate educacional que tensões se apresentam na proposição de políticas educacionais para projetos antagônicos de gestão

\footnotetext{
${ }^{11}$ Para essa diferenciação entre administração e deliberação toma-se a ideia de participação na deliberação, a partir do sentido dado por Avritzer (2000, p. 43-44) ao conceito de democracia deliberativa.
}

Ensaio: aval. pol. públ. Educ., Rio de Janeiro, v. 17, n. 64, p. 449-476, jul./set. 2009 
pública na educação e sistematizaram-se tais tensões numa matriz de referência. Com estes dois contextos apresentados, pode-se passar ao exercício da análise empírica dos resultados da ação do PT e do PFL em contextos municipais paranaenses.

\section{0 acesso à escola: políticas, prioridades e resultados}

Na questão do acesso a disputa entre projetos pode ser dimensionada de forma objetiva na capacidade de cada gestão universalizar ou não o atendimento. Tal condição pode ser vista de forma mais imediata quando se considera a oferta de vagas e o tipo de vaga ofertada; mas pode também contar com indicadores menos imediatos, como as condições de oferta e as estratégias de garantia da permanência dos alunos na escola.

Observou-se a questão do acesso nas etapas e modalidades de responsabilidade direta do âmbito municipal, considerando os seguintes aspectos: expansão da rede, distribuição da responsabilidade da oferta entre rede estadual e municipal, cobertura e condições das escolas. A Tabela 1 apresenta os indicadores relativos à movimentação da matrícula.

Tabela 1- Movimento da matrícula em Curitiba e Londrina - 2001-2004.

\begin{tabular}{lcc}
\hline Etapa/ modalidade & CURITIBA & LONDRINA \\
\hline Educação Infantil - cobertura & $32,5 \%$ & $39,8 \%$ \\
\hline Expansão - Rede Municipal & $38,2 \%$ & $10,3 \%$ \\
\hline Expansão - Rede Estadual & $-82 \%$ & $21,9 \%$ \\
\hline Expansão - privada & $-0,9 \%$ & $20 \%$ \\
\hline Expansão - conveniada & $0,7 \%$ & $2,8 \%$ \\
\hline Ensino Fundamental - cobertura & $100,5 \%$ & $105,8 \%$ \\
\hline Expansão - Rede Municipal & $12,8 \%$ & $2 \%$ \\
\hline Expansão - Rede Estadual & $-9,9 \%$ & $-5,8 \%$ \\
\hline Expansão - privada & $-4,1 \%$ & $2 \%$ \\
\hline Educação Especial & & \\
\hline Incluidos no EF & 289 & 168 \\
\hline Classe especial /esc. especial. & $0,20 \%$ & $9,50 \%$ \\
\hline Expansão - Rede Municipal & $26,7 \%$ & $57,5 \%$ \\
\hline Expansão - Rede Estadual & $-69,1 \%$ & $-14,6 \%$ \\
\hline Expansão - privada & $5,9 \%$ & $10,5 \%$ \\
\hline EJA & & \\
\hline Expansão - Rede Municipal & $-3,9 \%$ & $10,1 \%$ \\
\hline Expansão - Rede Estadual & $-60 \%$ & $-75 \%$ \\
\hline Expansão - privada & $-26 \%$ & $-41 \%$ \\
\hline Fontes: INEP ([2006?); & $-2004) ;$ & \\
\hline
\end{tabular}

Fontes: INEP ([2006?]); IBGE (2005); Curitiba (2001-2004); Londrina (2001-2005). Informações tabuladas pela autora (2008). 
0 acesso à educação infantil cresceu nas duas redes municipais. No caso de Curitiba o maior crescimento foi da rede pública municipal $(38,2 \%)$, com municipalização da oferta, pela extinção na rede estadual de 2.034 vagas no período; o que resultou em incremento de vagas novas municipais de $25 \%$. Este encerramento de vagas na rede estadual pode explicar o baixo crescimento (1\%) da cobertura nesta etapa da educação básica. No caso de Londrina, o crescimento da rede municipal também ocorreu, porém com o incremento de apenas mais $10 \%$ das vagas, Londrina não teve extinção de vagas na rede estadual, esta cresceu $21 \%$ no mesmo período. Isto pode indicar formas diferentes de negociação com o governo estadual.

A cidade de Londrina teve ainda um crescimento de $20 \%$ da matrícula na rede privada, 48\% deste atendimento foi em instituições conveniadas; neste caso a Secretaria Municipal de Educação de Londrina (SMEL) informa que 6.703 alunos da rede privada eram atendidos com subvenção social em 2004. No caso de Curitiba, as informações da Secretaria Municipal de Educação de Curitiba (SMEC) são de que 8.856 matrículas estavam em instituições conveniadas com o poder público em 2004, isto é, $39 \%$ da matrícula privada.

Tais dados sugerem uma opção pela ampliação da matrícula da rede pública como estratégia da administração do PFL para o atendimento da população. Esta opção ainda conta com certa diversificação do atendimento, que atende às demandas das famílias trabalhadoras: atendimento noturno; extensão da jornada diária nas unidades em que há demanda para 12 horas ( $8 \mathrm{~h}$ às $19 \mathrm{~h}$ ) e o atendimento no periodo de férias escolares. Tal diversificação não muda a amplitude da oferta de educação infantil mas, ao incorporar estratégias que dialogam com a ação social, tem uma dimensão de inclusão.

No ensino fundamental a cobertura é mais significativa. Ainda que nas duas cidades o porcentual tenha decréscimo, este indica uma provável regularização do fluxo. Observa-se um movimento de municipalização da oferta mais intenso em Curitiba onde a rede cresceu em $12,8 \%$ no periodo, enquanto a rede estadual teve decréscimo de quase 10\%. Interessa destacar que Curitiba e Londrina estavam entre as poucas cidades que resistiram, ao longo dos anos 1990, à municipalização completa das séries iniciais do ensino fundamental, conforme proposta do governo estadual paranaense, tendo mantido um crescimento de suas redes na medida da capacidade financeira dos municípios. Nesse período esta posição de resistência parece ter sido revista na capital.

No caso de Londrina, a rede municipal também teve incremento de matrícula no ensino fundamental, entretanto mais modesto, apenas de $2 \%$. 0 decréscimo da rede estadual na cidade também foi menor $(-5,8 \%)$. Neste caso a rede 
parece manter um crescimento mais independente das pressões estaduais pela municipalização, ainda que parte do incremento na rede municipal possa ser explicado pelo recuo da rede estadual.

Quanto à educação especial os dados do Censo Escolar identificam alunos incluídos apenas no ensino fundamental e a partir de 2004, ainda que seja uma informação muito pontual, o porcentual é um pouco maior em Londrina (0,6\%; 168 crianças) que em Curitiba (0,3\%; 289 alunos). 0 atendimento direto em classes ou escolas especializadas na rede municipal de Londrina teve um crescimento de 57\% no período, enquanto a rede estadual na mesma cidade decresce em $14,6 \%$, o que resultou em um saldo de 19 vagas públicas novas. No caso de Curitiba, a rede municipal cresceu em 26\%, mas a rede estadual diminuiu em 69\%, com isto, em número de vagas abertas, o aumento da rede municipal não chegou a cobrir 0 número de vagas encerradas na rede estadual, resultando num saldo negativo de 526 vagas públicas.

Na educação de jovens e adultos, as duas cidades apresentam um movimento de diminuição da oferta estadual e privada de EJA, porém na rede própria os movimentos são diferentes. Em Curitiba há uma diminuição de matrículas na rede municipal de quase 4\%. A oferta de EJA nas escolas municipais se faz no periodo noturno em 70\% das escolas por meio de programa específico e em alguns casos em parceria com a Secretaria de Estado da Educação (SEED/PR) e a Fundação Roberto Marinho (CURITIBA, 2003, p. 288). Ao incluir este atendimento em parceria, a SMEC informa que em 2003 as matriculas na EJA chegaram a 12.180 alunos. Em Londrina a matrícula na EJA aumentou em $10,1 \%$ no período aqui considerado. A Secretaria mantinha neste periodo oferta de EJA de $1^{\text {a }}$ a $4^{\text {a }}$ séries na zona urbana e rural e oferta de EJA de $5^{\text {a }}$ a $8^{\text {a }}$ série apenas na zona urbana, a prefeitura criou a partir de 2002 o programa de alfabetização, além de manter convênios com entidades não governamentais, o que em 2002 viabilizou o atendimento de 900 alunos. 0 crescimento da matrícula na rede municipal de Londrina e uma articulação com programa de renda mínima podem ser indícios de uma politica de EJA mais voltada à inclusão social. Entretanto se considerado o índice de analfabetismo de 3,4\% em Curitiba (IBGE, 2005) e de 7,1\% em Londrina (IBGE, 2005), as iniciativas resultaram igualmente insuficientes.

Outra forma de discutir a efetividade da política em termos de acesso é o dimensionamento das condições em que este foi viabilizado em cada uma das redes. Neste momento procura-se de modo mais incisivo a ação das administrações no provimento de melhores condições para as unidades educativas, questões que podem ter incremento visível e mensurável no percurso de uma gestão (Tabela 2).

Ensaio: aval. pol. públ. Educ., Rio de Janeiro, v. 17, n. 64, p. 449-476, jul./set. 2009 
Tabela 2 - Condições de oferta de educação básica nas redes municipais de Curitiba e Londrina.

\begin{tabular}{|c|c|c|c|c|c|c|}
\hline \multirow[b]{2}{*}{ Condições } & \multicolumn{3}{|c|}{ Curitiba } & \multicolumn{3}{|c|}{ Londrina } \\
\hline & 2001 & 2004 & Saldo & 2001 & 2004 & Saldo \\
\hline Escolas de ensino Fundamental & 132 & 161 & 29 & 97 & 81 & -16 \\
\hline Biblioteca & 80 & 72 & -8 & 69 & 67 & -2 \\
\hline Laboratório de Informática & 47 & 141 & 94 & 0 & 2 & 2 \\
\hline Quadra de Esportes & 115 & 137 & 22 & 45 & 65 & 20 \\
\hline Sala para TV/Vídeo & 14 & 18 & 4 & 26 & 23 & -3 \\
\hline TV/Video/ Parabólica & 0 & 118 & 118 & 7 & 65 & 58 \\
\hline Microcomputadores & 132 & 158 & 26 & 62 & 78 & 16 \\
\hline Acesso à Internet & 22 & 157 & 135 & 53 & 63 & 10 \\
\hline Centros Municipais de Educação Infantil * & 118 & 141 & 23 & 12 & 11 & -1 \\
\hline Laboratório Informática & 0 & 1 & 1 & 2 & 0 & -2 \\
\hline Sala de TV & 25 & 14 & -11 & 2 & 3 & 1 \\
\hline TV/Vídeo/Parabólica & 2 & 10 & 8 & 0 & 0 & 0 \\
\hline Microcomputadores & 0 & 47 & 47 & 0 & 11 & 11 \\
\hline Acesso à Internet & 0 & 7 & 7 & 0 & 11 & 11 \\
\hline Biblioteca & 3 & 1 & -2 & 3 & 2 & -1 \\
\hline Carga horária de atendimento & Horas & Horas & & Horas & Horas & \\
\hline Educação infantil - creche & 11 & 11 & & 11,9 & 11,9 & \\
\hline Educação infantil - pré-escola & 10,4 & 8,9 & & 5 & 5,1 & \\
\hline Ensino fundamental & 4,5 & 4,3 & & 4 & 4,1 & \\
\hline EF com atendimento integral (6h ou $8 \mathrm{~h}$ ) & 36 & 36 & & 4 & 4 & \\
\hline Relação alunos/ função docente professor & N. ${ }^{\circ}$ & N. ${ }^{\circ}$ & & N. ${ }^{\circ}$ & N. ${ }^{\circ}$ & \\
\hline Educação infantil & 76,6 & 62,6 & & 14,6 & 14,6 & \\
\hline Ensino fundamental & 19 & 18 & & 18 & 19 & \\
\hline EJA & 25 & 21 & & 26 & 22 & \\
\hline Educação Especial & 6 & 6 & & 4 & 4 & \\
\hline Relação aluno/ turma & N. ${ }^{\circ}$ & N. ${ }^{\circ}$ & & N. ${ }^{\circ}$ & N. ${ }^{\circ}$ & \\
\hline Educação infantil - creche & 22 & 23 & & 16 & 15 & \\
\hline Educação infantil - pré-escola & 28 & 30 & & 25 & 25 & \\
\hline Ensino fundamental & 30 & 28 & & 28 & 28 & \\
\hline
\end{tabular}

Fontes: INEP ([2006?]); IBGE (2005); Curitiba (2001-2004); Londrina (2001-2005). Informações tabuladas pela autora (2008).

Obs.: s.i. = sem informação. ${ }^{*}$ parte da oferta da pré-escola está nas escolas e parte está nas creches. 
No caso das unidades de ensino fundamental, as duas redes priorizam construção de quadras de esporte e a informatização, seja com a criação de laboratórios de informática (Curitiba), ou pela garantia de computadores com acesso à Internet. A existência de laboratório de informática pode indicar um processo de inclusão da informática no currículo da escola, enquanto a garantia de computadores com acesso à Internet pode favorecer o uso administrativo ou dar apoio ao professor. A expansão do acesso às novas tecnologias parece evidenciar, nas duas redes, certa secundarização das bibliotecas escolares. Em Curitiba o saldo de escolas de ensino fundamental com biblioteca é de menos oito e em Londrina, de menos seis, ainda que neste caso nos três primeiros anos tenha havido expansão das bibliotecas. Nas creches o saldo é de menos dois, em Curitiba, também com movimento descontínuo, e, em Londrina, o saldo é menos um, com incremento destes espaços nas creches até 2003 e refluxo no último ano.

Quanto à carga horária de atendimento, os dados da tabela 2 informam uma diminuição da média de horas/aula/dia na educação infantil em Curitiba, o que pode ser explicado pela opção de transferência de parte das vagas de pré-escola dos Centros de Educação Infantil para escolas de ensino fundamental com turno parcial. No caso de Londrina, o atendimento da pré-escola manteve-se em torno de cinco horas diárias.

A relação professor/aluno nas duas redes é muito parecida, há problema nos dois casos com as informações para educação infantil, pois nos Centros de Educação Infantil o atendimento às crianças é feito por educadores que não são do quadro do magistério. 0 número de alunos por turma revela condições um pouco diferentes nas duas redes. Em Curitiba o número de crianças por turma é maior em todos os anos, tanto na fase da creche, quanto da pré-escola; no caso do ensino fundamental a diferença entre as duas redes é muito pequena.

Ainda que os dados utilizados aqui possam ter problemas, optou-se pela fonte INEP, pois os relatórios das gestões são muito mais imprecisos. Além disto, a forma de coleta do Censo Escolar é a mesma em todo o país, portanto, ainda que se pudessem depurar as informações por fontes diretas, estes dados seriam indícios do que há de dados disponíveis para possível avaliação comparativa de política pública em educação.

Diante desse panorama, parece possivel concluir que, no que se refere ao acesso, os dois municípios respondem à população de forma muito parecida. $A$ coincidência de estratégias na priorização do ensino fundamental, na ampliação da educação infantil com atendimento principal à faixa etária de pré-escola, na ampliação da carga horária no ensino fundamental para parte da rede, na diver-

Ensaio: aval. pol. públ. Educ., Rio de Janeiro, v. 17, n. 64, p. 449-476, jul./set. 2009 
sificação de atendimento para responder demandas de grupos vulneráveis socialmente, pode ser resultado do contexto nacional de financiamento da educação que condiciona as respostas municipais; assim como pode indicar um consenso entre os grupos políticos sobre a necessidade de promover o acesso às vagas para crianças e adolescentes em idade escolar.

Por outro lado, o conjunto da política nos dois municípios parece conter nuances de diferenciação: no atendimento à educação infantil, ainda que com a mesma estratégia de parceria com organizações não governamentais, a cobertura em Londrina tinha crescido mais que em Curitiba. Na politica de EJA nas duas cidades, ainda que em modelos parecidos na administração do PT, o programa complementar conta com um financiamento para o pagamento de alfabetizadores e com uma articulação junto ao programa de renda mínima municipal, não encontrados em Curitiba. No caso do ensino fundamental, a rede de atendimento integral é maior na administração do PFL, ainda que em formatos diferenciados: contraturno; escola integral; atendimento em equipamentos municipais de apoio às escolas regulares. No caso da educação especial, o movimento em Londrina parece mais consistente no sentido de ampliar a oferta pública. Na relação com a rede estadual, observado o movimento de municipalização, parece que a administração petista ofereceu mais resistência que a pefelistas, dado que, no primeiro caso, a participação da rede municipal no total da matrícula pública na cidade é de $37 \%$, com crescimento de quatro pontos percentuais entre 2001 e 2004; no caso pefelistas, a participação da rede municipal na matrícula pública é de $41 \%$ em 2004, com crescimento de oito pontos percentuais neste mesmo periodo.

A avaliação da efetividade da política educacional em termos de cobertura no âmbito municipal, no contexto de um ciclo da administração, ainda que muitos dos movimentos possam ser explicados por indução da pauta nacional, revela que 0 movimento de expansão do atendimento é inegável, entretanto a opção por determinadas estratégias acelera ou redimensiona o que se entende por oferta de cada etapa ou modalidade de ensino.

\section{A gestão da rede municipal e da escola: democracia, hierarquia e deliberação}

Para subsidiar a análise comparativa, também neste âmbito, buscou-se quantificar informações que possam constituir indicadores que auxiliem na reflexão acerca da efetividade da ação governamental na democratização das redes de ensino. Tais indícios estão organizados no Quadro 2: 


\begin{tabular}{|lcc|}
\hline Indicadores & Curitiba & Londrina \\
\hline Sistema Municipal de Educação & Em discussão & Sim \\
\hline Plano Municipal de Educação & Não & Em discussão \\
\hline Conferência Municipal de Educação & 0 & 1 \\
\hline Conferências Realizadas entre 2001-2004 & 0 & 2 \\
\hline Conselho de Acompanhamento e Controle Social do Fundef & Sim & Sim \\
\hline Conselho da Alimentação Escolar & Sim & Sim \\
\hline Conselho Municipal de Educação & Não & Sim \\
\hline Conselhos Regionais de Educação & Não & Sim \\
\hline Eleição de diretores & Sim & Sim \\
\hline Lei institui a eleição de diretores & Sim & Sim \\
\hline Possibilidade de reeleição & Sim & Sim \\
\hline Porcentual de renovação das direções de escola no último pleito & $23 \%$ & $31 \%$ \\
\hline Conselho escolar & Sim & Sim \\
\hline Lei institui o conselho escolar & Não & Sim \\
\hline Membros no conselho (moda) & 15 & 8 \\
\hline Número de representantes de pais nos conselhos (média) & 4,15 & 4 \\
\hline Número de representantes de professores nos conselhos (média) & 3,22 & 4 \\
\hline Critério de paridade entre usuários e trabalhadores da escola & Não & Sim \\
\hline Segmento que presidia o conselho em 2004 & & \\
\hline Total de escolas ${ }^{12}$ & 161 & 81 \\
\hline Número de conselhos presididos por pais & 0 & 40 \\
\hline Número de conselhos presididos por professores & 0 & 25 \\
\hline Número de conselhos onde outro segmento preside & 0 & 8 \\
\hline Número de conselhos onde o diretor é o presidente & Sim & Sim \\
\hline Associação de Pais e Professores & Sim & Sim \\
\hline Subvenção Social às Associações & & \\
\hline
\end{tabular}

Quadro 2 - Características da gestão da rede municipal de ensino e da escola em Curitiba e Londrina - 2001-2004.

Fonte: Informações municipais organizadas pela autora (2008).

No âmbito da gestão da rede de ensino não se encontrou mecanismos de participação em Curitiba, além dos indicados na legislação federal, enquanto, em Londrina, a dinâmica de participação no sistema de ensino foi ampliada com a realização de Conferências deliberativas regulamentadas quando houve a definição do Sistema Municipal de Ensino além de manter em funcionamento regular o Conselho Municipal de Educação.

\footnotetext{
${ }^{12}$ Faltou informação de quatro conselhos de escolas municipalizadas em 2004 em Curitiba e informação de oito conselhos em Londrina.
} 
0 perfil de gestão da rede/sistema de ensino coaduna-se com o perfil das administrações a que pertencem. No caso curitibano a perspectiva de excelência técnica e a preocupação com a continuidade do planejamento consubstanciada no "Modelo Curitiba de Planejamento", faz com que a definição das políticas educacionais se faça no âmbito do executivo, ainda que, com a constituição de comissões para discussão, não tinha havido, até 2004, a institucionalização de espaços de participação deliberativos mais amplos ou representativos de diferentes segmentos. A constituição do sistema municipal esteve em discussão em Curitiba a partir de 2003 e 2004, porém não há informações oficiais sobre o processo que foi ultimado com a aprovação de lei municipal criando o Sistema Municipal de Ensino em dezembro de $2006^{13}$.

No caso londrinense, a perspectiva anunciada no plano de governo, que defendia uma perspectiva democrática e participativa de gestão da cidade, teve desdobramentos em termos da continuidade de práticas participativas já existentes na rede municipal e da institucionalização, via aprovação de legislação na Câmara Municipal, de mecanismos de participação para a gestão do sistema de ensino. A Lei de Criação do Sistema Municipal de Ensino de Londrina foi aprovada em 2002, após duas Conferências.

Quanto ao desenho do Sistema Municipal discutido nas duas cidades neste período, há algumas diferenças explícitas. Na Minuta de Curitiba (2004) e na Lei de Sistema de Londrina (2002) são órgãos de gestão do Sistema Municipal, a própria Secretaria e o Conselho Municipal de Educação; no caso de Londrina, a Conferência Municipal de Educação foi definida como "fórum máximo de deliberação dos princípios norteadores das ações das unidades escolares do sistema de Ensino, a ser realizada, no mínimo uma vez, no período correspondente a cada gestão municipal" (LONDRINA, Lei n. ${ }^{\circ} 9.012$, artigo 20); no caso de Curitiba a realização de conferência municipal estava indicada na minuta entre as formas de exercício da gestão democrática do ensino público municipal com a seguinte redação "participação de todos os segmentos da sociedade na Conferência Municipal, a ser realizada a cada dois anos." ${ }^{14}$ (CURITIBA, 2004, artigo 32). Ainda que a previsão na proposta curitibana seja de mais conferências, bianuais, contra conferências que podem ser quadrienais em Londrina, a perspectiva deliberativa não está indicada na gestão do PFL, e é explícita na lei aprovada em Londrina no periodo considerado.

Outra diferença interessante para refletir-se sobre a diferença de perspectivas é a definição do caráter do Conselho Municipal de Educação. Na Minuta de Curitiba (2004, art. 21), o Conselho era definido como:

\footnotetext{
${ }^{13} \mathrm{~A}$ lei foi aprovada em Curitiba já na conjuntura de outro governo, este não está em discussão neste artigo.

${ }^{14} 0$ texto aprovado em Curitiba em 2006 mantém a redação da minuta, mas inclui em capítulo sobre a Conferência a seguinte definição: "Fórum deliberativo dos princípios norteadores das ações das unidades da Rede Municipal de Educação, a ser realizada no mínimo uma vez a cada 2 anos" (CURITIBA, 2006, art. 60).
}

Ensaio: aval. pol. públ. Educ., Rio de Janeiro, v. 17, n. 64, p. 449-476, jul./set. 2009 
[...] órgão colegiado do Sistema Municipal de Ensino, de caráter permanente, autônomo e harmônico com a Secretaria Municipal de Educação, com funções normativas, deliberativa, consultiva, fiscalizadora, mobilizadora e de controle social, de forma a assegurar a participação da sociedade na gestão da educação municipal.

Chama a atenção a descrição do Conselho como um órgão fiscalizador e de controle social e ainda, ao mesmo tempo, harmônico com a SME. Tal característica não pode ser garantida por lei, pois, se as funções de fiscalização e controle social se realizarem, um conselho independente, poderia em determinados momentos ter posições harmônicas e, em outros, posições de conflito com o Executivo. Ainda que esta redação não tenha sido a aprovada na lei municipal posteriormente, o texto da minuta ajuda a dimensionar a diferença de concepção de gestão do sistema nas duas administrações aqui em debate. A Lei de Londrina alterou o caráter do Conselho Municipal de Educação, que já existia desde 1999, definindo-o como "deliberativo, normativo, consultivo e fiscalizador do Sistema Municipal de Ensino". (LONDRINA, 2002, art. 8).

No caso da gestão das escolas, nas duas cidades encontraram-se mecanismos semelhantes, conselhos de escola, eleição de diretores e associações com pais e professores, porém com diferenças na organização e no funcionamento destes. Nos conselhos escolares, há diferenciações sobre que aspectos do funcionamento do conselho são padronizados em cada uma das cidades. Em Londrina, o número de membros do conselho é uniforme (oito), sendo isto regulado na lei municipal de 1994, que instituiu os conselhos escolares. Em Curitiba, não há lei municipal, o que de certa forma centraliza as orientações na SMEC, se entendermos a Câmara como um espaço mais amplo de decisão, seria adequado haver uma lei municipal para os conselhos escolares. 0 número de conselheiros em Curitiba varia segundo o tamanho da escola, indo de cinco, em 19 escolas, a vinte e cinco, em 15 escolas.

Como a composição do conselho escolar em Londrina é fixa em todas as escolas, encontrase a mesma distribuição paritária entre professores, equipe pedagógica, direção, funcionários ou grupo de apoio operacional. Em Curitiba, isto é bastante variado e alguns conselhos contam com outros segmentos na sua composição como alunos, representantes de associação de moradores, membros da APPF. Há uma pequena presença de funcionários nos conselhos o que é resultado da terceirização dos serviços de merenda e de limpeza, diminuindo o quadro de funcionários municipais na escola. Em média os conselhos de Curitiba têm 1,3 representantes da equipe pedagógica; 3,2 representantes dos professores; 0,97 representantes dos funcionários, 2,8 representantes da equipe administrativa, 4,2 representantes dos pais e 2,8 representantes de outros segmentos. Considerando-se as médias, os conselhos não têm paridade entre membros da escola e usuários. Se os representantes de "outros segmentos" forem alunos, pais da APPF ou da associação de moradores, o que ocorre na maioria das vezes, os usuários têm maioria no conselho, entretanto se o representante de outros segmentos for um professor da APPF, os segmentos de trabalhadores da escola é que têm a maioria.

Ensaio: aval. pol. públ. Educ., Rio de Janeiro, v. 17, n. 64, p. 449-476, jul./set. 2009 
A duração dos mandatos é uniforme em Londrina (dois anos). Em Curitiba os mandatos variam entre dois e três anos, dois anos em 93 escolas e três anos em 64 escolas. As eleições em Londrina para o conselho escolar são concentradas, sendo que em 2004 houve eleição para todos os conselhos. No caso de Curitiba, os conseIhos renovam-se em datas variadas.

Até aqui aparece uma alta centralização no funcionamento em Londrina, e um funcionamento mais autônomo em Curitiba, entretanto, as posições se invertem quando se considera um aspecto relacionado mais diretamente à distribuição de poder no interior das escolas. Em Curitiba todos os conselhos têm como presidente o diretor da escola, no caso de Londrina, o conselho elege seu presidente. Em 2004 nenhuma escola tinha o diretor como presidente do conselho, apesar de a lei municipal não o proibir.

0 fato de haver conselhos escolares em funcionamento nas duas cidades é uma semelhança importante entre as duas administrações, aproximando-as; entretanto, a manutenção do diretor como presidente do conselho parece contribuir para diferenciar o contexto de funcionamento da gestão em cada cidade. No caso curitibano mantém-se uma hierarquia na participação que pode contribuir para uma perspectiva de participação subordinada, uma vez que o diretor muitas vezes é visto na comunidade escolar como quem melhor sabe o que a escola precisa. Se pensarmos a figura do diretor [e por extensão dos profissionais da escola] como a face do Estado realizando o direito à educação na unidade escolar, quando o diretor é 0 presidente do conselho escolar, a condição da participação dos usuários é sempre complementar à direção dada pelo poder público.

No caso das Associações de Pais e Mestres - denominação presente em Londrina, e seu equivalente em Curitiba, Associações de Pais, Professores e Funcionários - nas duas cidades estas são pessoas jurídicas de direito privado que podem ser parceiras de convênios com as prefeituras. Neste caso, o tratamento a estas instâncias é muito semelhante, inclusive com programas de subvenção instituidos que reforçam a presença destas instâncias no interior das escolas.

A efetividade das ações no ciclo de uma administração em relação à democratização da gestão das redes parece indicar uma ampliação dos mecanismos de participação e deliberação no âmbito na rede municipal de Londrina, ainda que estes não sejam resultado apenas da gestão do PT, foram nesta gestão institucionalizados e funcionaram regularmente; em contrapartida, na capital, a gestão do PFL, apesar de fazer um movimento de reconhecimento da necessidade da institucionalização de tais espaços, não concretizou tal perspectiva. No âmbito da escola as duas redes incorporaram a participação, neste aspecto também na rede de Londrina encontram-se indícios de uma perspectiva mais igualitária de participação, com maior renovação das direções escolares (31\% no último pleito) e de 
divisão do poder de decisão no interior da escola. Ainda que opte pelo controle das datas de eleição dos conselhos, pela garantia da paridade, pela definição $a$ priori do tamanho dos conselhos, estas medidas podem ser um meio de garantir que os mecanismos de participação estejam ao alcance dos usuários da escola pública. No caso de Curitiba, a participação ainda que conte com o instituto da eleição de diretores e dos conselhos escolares, nestes, há uma hierarquia na composição do conselho que revela uma forma de compreender a gestão a partir de uma hierarquia nas possibilidades da participação.

\section{0 financiamento da educação: investimento e perfil dos gastos}

Uma terceira chave para a constituição de indicadores no ciclo da administração refere-se ao investimento em educação e o perfil deste investimento. Para isto tomar-se-ão aspectos da receita vinculada à educação para dimensionar o esforço municipal quanto à disponibilidade orçamentária, o gasto/aluno/ano como síntese do esforço em termos de investimento frente ao crescimento do atendimento e o perfil deste gasto como um indício da qualidade do investimento.

0 incremento da receita ${ }^{15}$ vinculada à educação, apresentada em per capita na tabela 3, foi superior ao crescimento da receita geral nas duas cidades. Isto pode ser explicado pelo crescimento de 63\% dos recursos adicionais em Londrina, e do crescimento de $87 \%$ dos recursos adicionais em Curitiba. No caso da capital, a maior parte desses recursos advieram do Fundef, devido ao processo mais intenso de municipalização da matrícula, em Londrina, onde o processo de municipalização foi pequeno, houve decréscimo desta fonte $(-1,9 \%)$, a diferença nas receitas adicionais de Londrina deveuse ao incremento dos convênios. Novamente os dados parecem indicar maior esforço da administração petista na busca de receita pública para financiar a política social.

Tabela 3 - Receita municipal, por habitante e por matrícula, em Curitiba e Londrina, 2001-2004.

\begin{tabular}{lrrrrrr}
\hline Receita municipal & \multicolumn{3}{c}{ CURITIBA } & \multicolumn{3}{c}{ LONDRINA } \\
\cline { 2 - 7 } & 2001 & 2004 & $\%$ & 2001 & 2004 & $\%$ \\
\hline Impostos/ habitante & 611,1 & 648,7 & 6,2 & 459,5 & 560,0 & 21,9 \\
\hline Rec. vinculada*/ habitante & 177,1 & 205,1 & 15,8 & 144,7 & 186,2 & 28,7 \\
\hline Rec. vinculada*/ matrículas & 2489,5 & 2665,4 & 7,1 & $1.978,0$ & $2.541,9$ & 28,5 \\
\hline
\end{tabular}

Fontes: INEP ([2006?]); IBGE (2005); Curitiba (2001-2004); Londrina (2001-2005). Informações tabuladas pela autora (2008).

Obs.: *25\%, convênios e plus Fundef.

\footnotetext{
${ }^{15}$ Os valores foram atualizados segundo o Índice Nacional de Preços ao Consumidor (INPC), do IBGE, de dezembro de 2006.
} 
Se a análise da receita pode dar indícios do esforço municipal, provavelmente, para financiar a política pública, a análise da despesa avança no sentido de indicar as prioridades municipais na área educacional. A Tabela 4 revela um crescimento maior do per capita MDE/matrícula em Londrina, apesar de que, neste município, houve grande variação no recurso aplicado por aluno, diferente da capital que tem um crescimento constante. 0 gasto/aluno é maior em MDE do ensino fundamental em Londrina e significativamente maior em MDE de educação infantil em Curitiba. No caso de Curitiba, considerando o período de 2001-2004 há uma diminuição do gasto por matrícula na educação infantil, que pode estar relacionado às mudanças no tempo de atendimento das crianças na faixa da pré-escola, já mencionadas anteriormente.

Tabela 4- Despesa declarada em MDE, por matrícula, Curitiba e Londrina, 20012004.

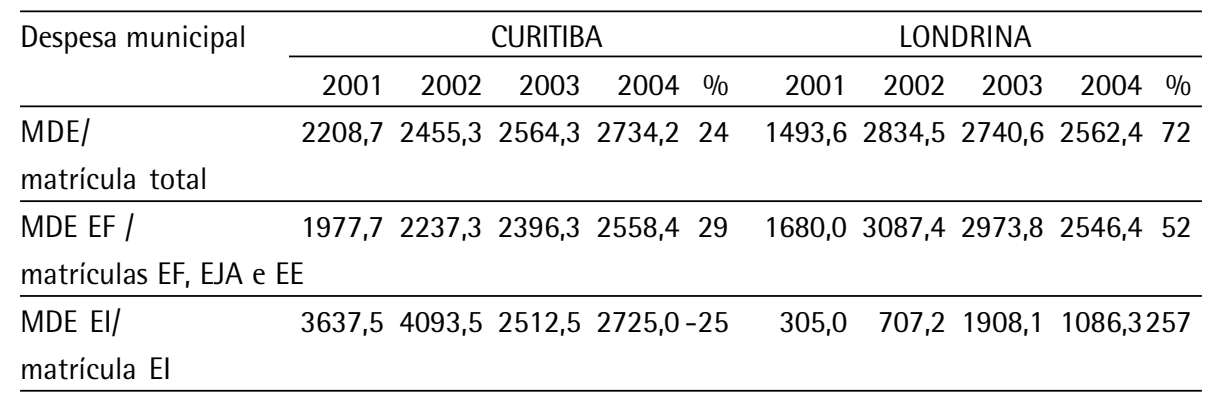

Fontes: INEP ([2006?]); IBGE (2005); Curitiba (2001-2004); Londrina (2001-2005). Informações tabuladas pela autora (2008).

Em relação à obrigatoriedade de aplicação de 25\% da receita de impostos, os gastos em MDE nas duas cidades tiveram muita flutuação. Em Curitiba, o porcentual aplicado foi de 21,7\% (2001); 25,0\% (2002) 26,2\% (2003) e 25,8\% (2004). 0 não cumprimento do mínimo constitucional foi um problema recorrente na gestão Taniguchi que levou, inclusive, à aprovação em 2003 de uma lei municipal definindo o conceito de MDE.

No caso de Londrina o porcentual aplicado foi de 28,3\% (2001); 30,7\% (2002); $32,9 \%$ (2003) e 25,7\% (2004). A flutuação da aplicação reflete o mesmo movimento de flutuação nos gastos por matrícula, embora a aplicação por matrícula cresça entre 2001 e 2004, em 72\%, isto se dá pelo crescimento da receita, pois a participação proporcional das despesas em MDE na receita diminui.

Tais dados parecem insuficientes para contrapor de forma categórica as administrações. Ainda assim, mostram tendências, pois mesmo que tenha havido aumento de investimento per capita nas duas cidades, este é maior em Londrina, 
podendo caracterizar o esforço de aumento de recursos pelo aumento da arrecadação, o que possibilita o investimento em educação sem impossibilitar o crescimento de investimento em outras áreas. Em Curitiba a tendência à economia de recursos pode ser vislumbrada ao considerar-se que a rede municipal teve um crescimento maior de alunos (15\%) que o de Londrina (6\%), com um crescimento de recursos menor, ainda que flutuante nos dois $\operatorname{casos}^{16}$.

0 perfil desses gastos também tem alterações nos dois municípios no período. Para analisar o perfil dos gastos, considerou-se o porcentual de despesas por categoria econômica, e na categoria "transferências correntes" optou-se por destacar algumas despesas que ajudam a caracterizar a mudança no funcionamento da máquina pública pela via dos processos de terceirização de serviços que, inclusive, têm impacto nas despesas com pessoal.

As duas redes têm uma diminuição dos gastos com pessoal civil no total das despesas. Em Curitiba tais gastos tiveram uma queda de 20 pontos percentuais e em Londrina de 14 pontos. Em contrapartida as transferências correntes dobraram sua participação na despesa em Curitiba e fecharam o período em Londrina, com crescimento de cinco pontos percentuais. Quando se desdobram as despesas em transferências correntes, 0 maior crescimento em Londrina foi de recursos de subvenção social, mas há também um crescimento descontínuo dos serviços de terceiro. Em Curitiba cresceram as despesas com serviços de terceiro e locação de mão de obra, na capital todo o serviço de alimentação escolar, limpeza e segurança já estava terceirizado no período.

Tabela 5- Porcentual de participação das despesas por categoria econômica na despesa da Secretaria Municipal de Educação; Curitiba e Londrina, 2001-2004.

\begin{tabular}{lcccc}
\hline & \multicolumn{2}{c}{ Curitiba } & \multicolumn{2}{c}{ Londrina } \\
\hline CATEGORIA ECONÔMICA & 2001 & 2004 & 2001 & 2004 \\
\hline DESPESAS CORRENTES & & & & \\
\hline Pessoal & 69,1 & 49,6 & 77,6 & 63,5 \\
\hline Material de Consumo & 9,6 & 9,5 & 2,9 & 9,7 \\
\hline Transferências correntes & 17,8 & 35,5 & 18,8 & 23,6 \\
\hline Subvenções sociais & 1,9 & 1,6 & 1,7 & 8,9 \\
\hline Outros serviços de terceiros - pessoa física & 0,4 & 0,3 & 1,1 & 0,2 \\
\hline Locação de mão de obra & 4,9 & 6,1 & - & - \\
\hline Outros serviços de terceiros - pessoa jurídica & 10,6 & 23,5 & 6,1 & 6,1 \\
\hline DESPESAS DE CAPITAL & 3,4 & 5,4 & 0,7 & 3,3 \\
\hline
\end{tabular}

Fontes: INEP ([2006?]); IBGE (2005); Curitiba (2001-2004); Londrina (2001-2005). Informações tabuladas pela autora (2008).

\footnotetext{
${ }^{16}$ Cabe destacar que os per capita na capital são sempre maiores que em Londrina, o que tem relação com a disponibilidade maior de recursos por habitante na capital que no interior. Devido à concentração da riqueza gerada pelo sistema tributário em vigor, optou-se por analisar o movimento do financiamento em cada cidade e não destacar o per capita aluno ano em si, posto que, neste caso todos os indicadores seriam de melhores condições em Curitiba independente da ação governamental.
} 
Enfim, enquanto o âmbito do acesso à escola aproximou as duas administrações e o âmbito da gestão permitiu diferenciá-las, o âmbito do financiamento, mais indefinido, apresenta nuances que podem tanto atestar a aproximação da gestão do PT a teses da esquerda acerca do aumento de recursos para educação, quanto podem atestar a submissão a teses da direita em relação ao enxugamento do Estado. 0 primeiro movimento pode ser flagrado num aumento dos percentuais de gastos na função educação, ainda que de forma descontínua; no investimento maior por aluno/ano, também descontínuo. 0 segundo movimento pode ser flagrado no enxugamento, ainda que um pouco menor que o de Curitiba, dos gastos com pessoal e pouco menor com transferências correntes.

No sentido invertido o âmbito do financiamento contém nuances quanto ao movimento do PFL de ceder a teses da esquerda, aumentando, mesmo que em valores discretos, a aplicação de recursos anuais por aluno; mas contém nuances também da incorporação nessa gestão das teses da direita quanto ao enxugamento do Estado flagrados no descumprimento da vinculação constitucional, na diminuição significativa dos gastos com pessoal civil versus um aumento dos gastos com transferências correntes.

\section{Considerações finais}

A intenção central deste artigo foi apresentar indicadores de política educacional no âmbito do acesso, da gestão e do financiamento. Tais indicadores pretendem contribuir na construção de metodologia de avaliação da política educacional em termos da sua efetividade objetiva, por isto a preocupação em indicar elementos mensuráveis em cada âmbito. Certamente isto deixa uma expectativa sobre o quanto tais elementos interferem ou contribuem para a qualidade da formação dos estudantes matriculados nestas redes de ensino, ou seja, afora os insumos para o processo educativo quais são os resultados das políticas em termos de qualidade de ensino?

A pesquisa que sustenta este artigo tinha como foco uma discussão de insumos e, neste aspecto, debruçou-se sobre aspectos referentes à gestão e ao financiamento e, em termos de resultados a única medida foi em termos de acesso à escola. Compreende-se que uma discussão acerca da qualidade de ensino implicaria análises do processo pedagógico. Tal processo é difícil de ser mensurado e os indicadores para isto não são consensuais na área da educação.

Ainda assim, uma possibilidade de indicador para subsidiar a comparação entre as redes, disponivel neste momento, poderia ser o Índice de Desenvolvimento da Educação (IDEB) construído pelo Ministério da Educação e divulgado recentemente. Ainda que sobre tal índice pesem inúmeras dúvidas, críticas e polêmicas, optou-se por inclui-lo aqui como mais um indício.

Ensaio: aval. pol. públ. Educ., Rio de Janeiro, v. 17, n. 64, p. 449-476, jul./set. 2009 
Segundo as informações disponíveis no sistema de consulta do INEP, os IDEBs para as séries iniciais do ensino fundamental, em Curitiba e em Londrina, para o ano de 2005, foram, nos dois casos, de 4,7. Para as séries finais do ensino fundamental, a cidade de Curitiba teve um índice de 4,2 e Londrina de 3,8. As duas redes municipais tiveram índices superiores ao IDEB da rede estadual paranaense que foi de 3,3 para $5^{\mathrm{a}}$ a $8^{\mathrm{a}}$; e as duas redes municipais têm indices menores que a rede estadual no caso das séries iniciais, neste caso o índice da rede estadual é de 5,0. Assim pode-se argumentar que apesar da diferença de perspectivas de gestão, em termos de resultados escolares os esforços das administrações tem efeitos parecidos. Entretanto, aqui parece que para de fato estabelecer-se um debate mais consistente entre perfil partidário e resultados escolares não há dados suficientes para tal empreitada, ainda que tal relação possa ser uma questão para uma agenda de pesquisa na área de política educacional.

Finalmente, cabe ainda destacar que o esforço da pesquisa aqui apresentada relacionava-se com duas preocupações, primeiro com o fato de que o grau de descentralização da oferta educacional brasileira resulta que os municípios são hoje campo fundamental de definição da política educacional e, neste campo, diferentes sujeitos coletivos têm definido prioridades de atendimento, desenhos institucionais de gestão e prioridades de alocação de recursos; segundo, que o ciclo da administração pública, ainda que possa não ser o tempo da efetivação dos resultados das políticas, tem historicamente sido o tempo de alterações de rumos das políticas educacionais.

A discussão de metodologias de avaliação de política educacionais que possam conter informações mais precisas acerca dos efeitos das administrações, na realidade das redes municipais parece poder contribuir para definição de parâmetros mais explícitos de qual é o padrão de condições para qualidade de ensino a ser buscada em cada contexto particular. Para isto, apresentou-se ao longo deste artigo alguns indicadores que foram testados em dois contextos municipais com administrações de perfis diferentes no espectro político brasileiro. Os resultados encontrados na pesquisa de campo parecem confirmar o potencial destes indicadores para diferenciar os efeitos das administrações, entretanto, além deste debate carecer de mais casos para comparação, parece pertinente que se avance coletivamente no debate sobre a validade de tais indicadores.

Ensaio: aval. pol. públ. Educ., Rio de Janeiro, v. 17, n. 64, p. 449-476, jul./set. 2009 


\section{Referências}

AVRITZER, L. Teoria democrática e deliberação pública. Lua Nova, São Paulo, n. 50, p. $25-46,2000$.

ADRIÃO, T. Educação e produtividade: a reforma do ensino paulista e a desobrigação do Estado. São Paulo: Xamã, 2006.

AFONSO, A. J. Avaliação educacional: regulação e emancipação. São Paulo: Cortez, 2002.

CURITIBA (PR). Balanço orçamentário anual 2001. Curitiba, 2002. Disponível em: <http://sitepmcestatico.curitiba.pr.gov.br/servicos/financas/orcamento/ index.htm>. Acesso em:15 set. 2009.

Balanço orçamentário anual 2002. Curitiba, 2003. Disponível em: <http://sitepmcestatico.curitiba.pr.gov.br/servicos/financas/orcamento/ index.htm>. Acesso em: 15 set. 2009.

Balanço orçamentário anual 2003. Curitiba, 2004. Disponível em: <http://sitepmcestatico.curitiba.pr.gov.br/servicos/financas/orcamento/ index.htm>. Acesso em: 15 set. 2009.

Balanço orçamentário anual 2004. Curitiba, 2005. Disponível em: $<$ http://sitepmcestatico.curitiba.pr.gov.br/servicos/financas/orcamento/ index.htm>. Acesso em; 15 set. 2009.

. Lei n. ${ }^{0} 12.090$, de 19 de dezembro de 2006. Dispõe sobre a Organização do Sistema Municipal de Ensino. Sistema de Proposições Legislativas, Curitiba, 20 dez. 2006. Disponivel em: <http://www.cmc.pr.gov.br/spl.htm>. Acesso em: 17 jul. 2007.

Prefeitura. Instituto Municipal de Administração Pública. Relatório anual, 2003. Curitiba, 2003. Disponível em: <www.imap.org.br>. Acesso em: mar. 2006.

Prefeitura. Secretaria Municipal de Educação. Minuta do Projeto de Lei do Sistema Municipal de Ensino. Curitiba, 2004. Mimeografado.

FIGUEIREDO, A. M. C.; FIGUEIREDO, M. F. Avaliação política e avaliação de políticas: um quadro de referência teórica. Análise e Conjuntura, Belo Horizonte, v. 1, n. 3, p. 107-127, set./dez. 1986.

FIGUEIREDO, A. M. C. Princípios de justiça e avaliação de políticas. Lua Nova, São Paulo, n. 39, p. 96-103, 1997. 
FLEISCHER, D. V. As eleições municipais no Brasil: uma análise comparativa (1982-2000). Opinião Pública, Campinas, SP, v. 8, n. 1, p. 80-105, 2002.

FPA. Fundação Perseu Abramo, [S.I.], 2007. Disponível em:

<www.fpabramo.org.br>. Acesso em: 8 set. 2009.

IBGE. Censo demográfico 2000. Rio de Janeiro, 2001. Disponivel em: <http:// www.ibge.gov.br/censo/divulgacao_impresso.shtm >. Acesso em: 15 set. 2009.

Pesquisa Nacional por Amostra de Domicílios 2004. Rio de Janeiro, 2005. Disponivel em: <www.ibge.gov.br/home/.../pnad2005/default.shtm>. Acesso em: 15 set. 2009.

INEP. Sistema de Estatísticas Educacionais. Edudatabrasil, Brasília, DF, [2006?]. <http://www.wdudatabrasil.inep.gov.br>. Acesso em: 15 set. 2009.

ITN. PFL em Debate, Rio de Janeiro, 2007. Disponível em: <www.rj.itn.org.br/ PFLRJ/PFLdebates.htm>. Acesso em: 8 set. 2009.

KECK, M. E. PT: a lógica da diferença: o Partido dos Trabalhadores na construção da democracia brasileira. São Paulo: Ática, 1991.

MAINWARING, S.; MENEGUELLO, R.; POWER, T. Partidos conservadores no Brasil contemporâneo: quais são, o que defendem, quais são suas bases. São Paulo: Paz e Terra, 2000.

LIMONGI, F.; FIGUEIRED0, A. C. Partidos políticos na Câmara dos Deputados: 1989-1994. Dados, Rio de Janeiro, v. 38, n. 3, p. 497-525, 1995.

Balanço orçamentário anual 2001. Londrina, 2001. Mimeografado.

Balanço orçamentário anual 2002. Londrina, 2002. Mimeografado.

Balanço orçamentário anual 2003. Londrina, 2003. Mimeografado.

LONDRINA (PR). Prefeitura. Relatório anual. Londrina, 2001. Mimeografado.

Prefeitura. Relatório anual 2001. Londrina, 2001. Mimeografado.

Prefeitura. Relatório anual 2002. Londrina, 2002. Mimeografado.

Prefeitura. Relatório anual 2003. Londrina, 2003. Mimeografado. 
LONDRINA (PR). Prefeitura. Relatório anual 2003. Londrina, 2003. Mimeografado. . Balanço orçamentário anual 2004. Jornal Oficial do Município, Londrina, n. 631, 31 jan. 2005. Edição extra.

Lei Municipal no. 9.012, de 23 de dezembro de 2002. Cria e organiza o Sistema de Ensino do Município de Londrina e o Conselho Municipal de Educação. Diário Oficial do Município, Londrina, 26 dez. 2002.

PARO, V. Administração escolar. introdução crítica. São Paulo: Cortez, 1996.

PERONI, V. Política educacional e papel do Estado no Brasil dos anos 1990. São Paulo: Xamã, 2003.

RAICHELIS, R. Gestão pública e a questão social na grande cidade. Lua Nova, São Paulo, n. 69, 2006. Acesso em: 3 dez. 2007.

RODRIGUES, L. M. Partidos, ideologia e composição social: um estudo das bancadas partidárias na Câmara dos Deputados. São Paulo: EDUSP, 2002.

SAMUELS, D. As bases do petismo. Opinião Pública, Campinas, SP, v. 10, n. 2, p. 221-241, out. 2004.

SANTOS, F.; VILAROUCA, M. G. Desigualdade e política partidária no Brasil contemporâneo. In: SCALON, C. Imagens da desigualdade. Belo Horizonte, MG: UFMG: IUPERJ: UCAM, 2004.

SANDER, B. Políticas públicas e gestão democrática da educação. Brasilia, DF: Liber Livro, 2005.

SCALON, C. Imagens da desigualdade. Belo Horizonte: UFMG: IUPERJ: UCAM, 2004.

TAROUCO, G. S. Fatores do desenvolvimento do Partido da Frente Liberal. In: PINTO, C. R. J.; SANTOS, A. M. Partidos no Cone Sul. Rio de Janeiro: Fundação Konrad Adenauer, 2002.

Recebido em: 17/10/2008

Aceito para publicação em: 04/05/2009 